Article

\title{
IoT-Based Intelligent Construction System for Prefabricated Buildings: Study of Operating Mechanism and Implementation in China
}

\author{
Xuetong Wang ${ }^{1}\left(\mathbb{D}\right.$, Shuiling Wang ${ }^{1} \mathbb{D}$, Xiangnan Song ${ }^{1, * \mathbb{C}}$ and Yilong Han ${ }^{2}$ \\ 1 School of Management, Guangzhou University, Guangzhou 510006, China; xtwang@gzhu.edu.cn (X.W.); \\ 2111865016@e.gzhu.edu.cn (S.W.) \\ 2 School of Economics and Management, Tongji University, Shanghai 200092, China; yilong.han@tongji.edu.cn \\ * Correspondence: songxn@gzhu.edu.cn
}

Received: 14 August 2020; Accepted: 9 September 2020; Published: 10 September 2020

check for updates

\begin{abstract}
At present, the low degree of informatization in the construction industry chain is one of the prominent problems impeding the application efficiency of prefabrication. To break through the bottleneck of information integration and interaction in the construction process of prefabricated buildings, this paper proposes a conceptual framework of an Intelligent Construction System for Prefabricated Buildings based on the Internet of Things (ICSPB-IoT) according to the needs of government supervision departments, contractors and owners. Then this paper describes the formation of the "information network" from "information flow", based on which the operating mechanism of the ICSPB-IoT is discussed using the method of system engineering analysis. Finally, the proposed ICSPB-IoT is graded into different implementation levels according to the degree of intelligence of the Internet of Things information, and the implementation path is proposed for construction enterprises with different levels of digitalization. The results show that the ICSPB-IoT provides cross-phase, cross-organizational information interaction for government supervision departments, contractors and owners to improve the efficiency of communication and collaboration between them. This paper also provides decision-making support for the design, layout and implementation of the Internet of Things for prefabrication construction enterprises.
\end{abstract}

Keywords: IoT; prefabricated buildings; information integration and interaction; intelligent construction system

\section{Introduction}

Prefabricated buildings, as one practice of designed building components being made in factories in advance and then transported to the construction site for assembly, have been widely promoted across the world as one of sustainable construction methods for their advantages of a short construction period on-site, high quality, low cost and less energy consumption [1,2]. It has also been reported that the global prefabricated buildings market was USD 159 billion in 2017, a substantial increase of more than $20 \%$ from the previous year [3], and which is expected to grow at a CAGR (Compound Annual Growth Rate) of over 8\% during the period 2019-2025 [4]. Moreover, it is anticipated that the area of prefabricated buildings in China will be more than 200 million square meters every year after 2020 [5].

However, with the popularization and application of prefabricated buildings in practice, it is increasingly found that the low degree of informatization in the construction industry chain is one of the prominent problems impeding the application efficiency of prefabrication [6,7]. Although some efforts have been made to facilitate information exchange through various emerging technologies (e.g., building information model (BIM) [8,9], radio frequency identification technology (RFID) [10,11], 
the global positioning system (GPS) [12]), the integration, interaction and collaboration of the upstream and downstream enterprises in the industrial chain have not been fully achieved [13]. In addition, the frequent occurrence of information interruption among different stakeholders makes it very difficult to control and trace the quality and safety of construction processes [14]. Only if information is shared at all stages of design, component prefabrication, transportation and assembly, can we effectively minimize loss and waste in prefabricated buildings.

Under the context of Industry 4.0, a new round of science and technology revolution, the construction industry faces a historic opportunity to undergo a deep digital transformation and upgrading $[15,16]$. The fusion of various emerging information technologies makes intelligent construction possible. To be specific, intelligent construction can be defined as the next-generation information technologies characterized by "three modernization" (i.e., digitization, network and intelligence), which are used to realize the digital transformation of the elements and resources in construction. This lays a solid foundation for standardized modeling, networked interaction, visual cognition, high-performance computing and intelligent decision-making in the whole construction process [17]. On this basis, a highly efficient and coordinated construction with an integration of project planning, design, build, operation and maintenance can be achieved. This new mode of construction provides the future development direction of prefabricated buildings. The Internet of Things (IoT), as a core part of emerging information technologies, integrates many acquisitions, communication and computing technologies [18]. It not only makes communication between people more convenient, but also enables the exchanges between people and things as well as things and things, which drives the integration of human society, information space and the physical world (i.e., human-machine-object) [19]. Therefore, applying the IoT technology to the intelligent construction system of prefabricated buildings will significantly contribute to breakthroughs tackling the current bottleneck in information interaction in prefabricated buildings.

The IoT-based Intelligent Construction System for Prefabricated Buildings (ICSPB-IoT) is a system which integrates both information science development achievements and modern construction industry technologies [20]. Specifically, the essence of ICSPB-IoT is to achieve the efficient management of engineering quality, safety, cost and schedule through the intelligent interconnection and collaborative interaction of "entities" (i.e., things involved in completing a certain task, such as resource elements, subsystems, etc.) in the process of prefabricated buildings by comprehensively applying technologies including RFID, machine vision, sensor, GPS, and network communication. For instance, through the integrated application of different IoT technologies, it is possible to achieve an intelligent operation of the position tracking of prefabricated buildings components [12], quality traceability [6], component manufacturing [21,22], storage [23], transportation and field lifting [8,14]. In particular, the monitoring of the whole construction process effectively strengthens the coordination and communication between all stages of prefabricated buildings, which significantly improves the work efficiency and reduces the occurrence of information asymmetry and interruption. The IoT helps prefabricated buildings transition toward intelligence and information-oriented development. Therefore, the systematic exploration into the principles of ICSPB-IoT and operating mechanisms of ICSPB-IoT is of great theoretical and practical significance for reducing the cost, ensuring the quality and safety, and promoting the intelligent construction of prefabricated buildings.

This paper is arranged as follows: First, in Section 2, the literature about intelligent developments in prefabricated buildings, the application of IoT in prefabricated buildings, and the development of intelligent construction systems is reviewed. Then, the conceptual framework of the ICSPB-IoT is introduced, and its system compositions are analyzed in Section 3. The operating mechanism of the ICSPB-IoT in each stage is analyzed in Section 4. Finally, in Section 5, the implementation path of the ICSPB-IoT is proposed and the difficulties that may be encountered are discussed, which is followed by a conclusion section in Section 6. 


\section{Background}

Intelligent construction is an innovative concept in the advancement of the construction industry [24]. On the one hand, intelligent construction can help construction companies save resources and increase productivity during construction. On the other hand, the information management, achieved by using the new technologies (e.g., sensors and controls, cognitive and high-performance computing, additive manufacturing, advanced material autonomous robots, digital design and simulation systems) [15], can improve project productivity and quality, reduce project duration and cost, lessen the complexity of project management, and enhance site safety for promoting the sustainable development of the construction industry $[25,26]$. Specifically, Niu et al. [27] pointed out that the IoT empowers construction resources (e.g., machinery, tools, device, materials, components, and even temporary or permanent structures) with capacities of sensing, processing and communication, making them smart construction objects (SCOs) with autonomy, consciousness and communication. Furthermore, Li et al. [28] combine SCOs with smart gateways to form an intelligent construction environment, enabling SCOs to perceive and interact with each other. All these laid a theoretical foundation for the intelligent construction of prefabricated buildings. In some other studies, the equipment, models and ideas utilized for the intelligent construction of prefabricated buildings have been invented or proposed. For example, Cho et al. [29] developed a new intelligent construction lift car toolkit for vertical material movement management at a construction site. Tae-Hong et al. [30] proposed a supply chain management model for intelligent construction. Xu et al. [6] developed an intelligent construction management platform for prefabricated buildings based on lean construction concepts and achieved good results in practice.

With the rapid development of sensors and network information technologies, IoT has played an essential role in almost all fields [31]. It not only facilitates the visualization and traceability of workflows, but also promotes information integration and big data analysis [32,33]. The IoT has been applied at different levels of intelligent construction of prefabricated buildings, such as the unit level (e.g., prefabricated components), system level (e.g., construction system) and complex system level (e.g., construction site), as shown in Table 1.

Table 1. The application of Internet of Things (IoT) in different levels in prefabricated buildings.

\begin{tabular}{lll}
\hline \multicolumn{1}{c}{ Application Level } & \multicolumn{1}{c}{ Description } & \multicolumn{1}{c}{ References } \\
\hline Prefabricated components & $\begin{array}{l}\text { Identify, locate and track prefabricated } \\
\text { components through the connectivity of the IoT } \\
\text { to realize the visualization and traceability of } \\
\text { component information and further improve the } \\
\text { prefabricated supply chain system. }\end{array}$ & {$[12,34,35]$} \\
\hline & $\begin{array}{l}\text { Plan and optimize the construction process } \\
\text { through real-time collection, integration and } \\
\text { interaction of construction production } \\
\text { process information. }\end{array}$ & {$[6,8,14,21,36]$} \\
\hline \multirow{3}{*}{ Construction system } & $\begin{array}{l}\text { Realize the intelligent management, control and } \\
\text { optimization of the construction process for the } \\
\text { smart construction site. }\end{array}$ & {$[37-40]$} \\
\hline
\end{tabular}

Regarding the level of prefabricated components, the IoT, RFID and GPS can help to realize the functions of identification, tracking, and positioning in construction [12]. Ma et al. [34] improved the traceability of prefabricated components by a secondary development of Revit to provide a basis for quality responsibility tracking in the later period, reducing the unnecessary waste of human and material resources and helping to maximize economic benefits. Similarly, Du et al. [35] proposed the information tracking and supply mechanism for the prefabricated supply chain to facilitate the information interaction between the upstream and downstream industry chains. With regard to the construction system level, Yin et al. [21] developed a prefabricated production management system 
supported by the IoT to control and optimize the production process of prefabricated components. $\mathrm{Hu}$ and $\mathrm{Lu}$ [36] designed and implemented a new management system based on the IoT to trace the manufacturing process, optimize the manufacturing schedule and analyze product quality problems for controlling product quality. Li et al. [8] designed a platform supported by the IoT to optimize the workflow of prefabricated structures' field assembly. In order to further improve the construction efficiency, a BIM platform supported by the IoT was developed by Xu et al. [6] and Zhong et al. [14] to realize the visibility and traceability of the construction process and share the information between stakeholders on the platform. As to the construction site level, Zhou et al. [37] proposed the concept of a smart construction site and summarized the key elements. For improving construction efficiency and flexibility, Yu et al. [38] combined technologies of the Internet, 3D scanning, BIM, virtual reality, augmented reality and IoT technologies to propose a BIM-based field management model that can more intelligently manage information related to human resources, mechanical and resource allocation, quality control, site supervision, and safety supervision. Kim et al. [39] place extra emphasis on achieving task management and real-time information sharing of the construction site. Similarly, Kochovski and Stankovski [40] developed a reliable edge computing infrastructure and applications further to support high-quality, intelligent construction environments.

Even though previous research has investigated the application of the IoT in the intelligent construction of prefabricated buildings, most studies are limited at one or two aspects of the IoT. In fact, an ICSPB-IoT is a complex system with various goals. The quality traceability system, assembly service system or supply chain management system investigated by previous studies is just one of the application tasks, while a high-level ICSPB-IoT should achieve an all-around, multisystem or multiplatform interaction and integration. Besides, the service objects, application stages and functions of the IoT in the previous studies are relatively single-mentioned, and most of them are gathered at the component production and on-site assembly stage. A high-level ICSPB-IoT should provide a series of services (e.g., integration design, lean production, transparent transportation, visual assembly, and intelligent building) for the lifecycle of the prefabricated buildings, which covers all participants, including the government, contractors, and owners. Therefore, despite many efforts, there are still knowledge gaps. Specifically, they can be summarized as the following research problems and corresponding solutions in this paper. First: how to develop an information management system that can serve the participants of prefabricated buildings, so as to enhance the ability to make collaborative decisions. The ICSPB-IoT proposed in this paper is an integrated decision-making service system for data collection, processing and analysis of prefabricated buildings, which enables governments, contractors and owners to interact with information in the ICSPB-IoT for controlling the progress of the project in real-time. Then: how to realize the information exchange and functional service of the participants by the ICSPB-IoT. This article discusses the functional requirements of each participant, and then divides the system into three blocks to serve the government, contractors, and owners. The data of the three blocks are all derived from the project level information center, which provides support for the information exchange between the participants to achieve an integrated design, lean production, transparent transportation, visualization assembly, intelligent building and other goals. Finally: how to implement the ICSPB-IoT to promote the intelligent development of prefabricated buildings. This article, based on the existing research, divides the ICSPB-IoT into six levels according to the intelligence of information, and determines ten steps to implement an ICSPB-IoT. This provides a reference value for prefabricated construction companies to set up an ICSPB-IoT.

\section{Development of the ICSPB-IoT Conceptual Framework}

An ICSPB-IoT, as a complex project with multiple entities, systems and functions, provides many platforms for users to improve the effective coordination and precise control of the construction processes. The ICSPB-IoT aims to ensure that the information of the whole construction process is always in a shared environment to optimize construction management, improve engineering quality and minimize prefabricated building costs. In order to avoid the readers' misunderstanding of the 
participants' management tasks caused by the distinctiveness in the systems and cultural backgrounds of different countries, this paper takes China as an example to classify the participants, including owners, government regulators and contractors (subcontractors), and explains their main tasks, as shown in Table 2. The design of an ICSPB-IoT should consider the functional requirements of the users.

Table 2. The main tasks of participants.

\begin{tabular}{|c|c|c|c|}
\hline \multicolumn{2}{|c|}{ Participants } & Tasks & Main Experience Stage \\
\hline \multicolumn{2}{|c|}{ Owners } & $\begin{array}{l}\text { Responsible for the whole process } \\
\text { management of the project, including } \\
\text { interorganizational coordination, } \\
\text { material and craftwork supervision, cost } \\
\text { control, on-site decision-making, etc. }\end{array}$ & All stages \\
\hline \multicolumn{2}{|c|}{ Government regulators } & $\begin{array}{l}\text { Manage and supervise the overall } \\
\text { quality and safety production of local } \\
\text { construction projects. }\end{array}$ & Component production and lifting stage \\
\hline \multirow{5}{*}{ 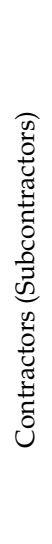 } & Designers & $\begin{array}{l}\text { Mainly responsible for providing design } \\
\text { drawings to the owners, coordinating } \\
\text { and completing design changes from } \\
\text { the constructors and manufacturers. }\end{array}$ & Design stage \\
\hline & Constructors & $\begin{array}{l}\text { Mainly control the quality, schedule and } \\
\text { cost in the construction process, and } \\
\text { manage the construction contract, } \\
\text { information and site safety. }\end{array}$ & Lifting stage \\
\hline & Supervisors & $\begin{array}{l}\text { Entrusted and authorized by the owner } \\
\text { to supervise and manage the whole } \\
\text { construction project. }\end{array}$ & Lifting stage \\
\hline & $\begin{array}{l}\text { Component } \\
\text { manufacturers }\end{array}$ & $\begin{array}{l}\text { Make prefabricated parts according to } \\
\text { design documents. }\end{array}$ & Component production stage \\
\hline & Logistics carriers & $\begin{array}{c}\text { Delivery of prefabricated parts to the } \\
\text { construction site. }\end{array}$ & Transportation stage \\
\hline
\end{tabular}

\subsection{Demand Analysis of the Main Stakeholders}

From the owners' point of view, engineering quality is one of their most important objectives [41], and intelligence is the key to improving the quality [42,43]. To be specific, traditionally, it is extremely difficult for owners to know whether the building has hidden safety hazards just from the appearance. Hence, it is crucial to realize the whole process of information traceability from design to complete acceptance. Driven by the IoT technology, "digital + physical" (i.e., digital engineering product) delivery can be realized, which not only meets the owner's demand for accessing the building's quality information, but also serves as a tool to monitor the quality of the building from the initial construction stage. Besides, the IoT-based building and digital connectivity mechanism enable the real-time monitoring and remote control of building components.

From the perspective of the contractors, information sharing is the prerequisite for the work to be carried out effectively, and benefit maximization is their key goal $[6,14]$. The resource elements (e.g., man, machine, material, method, environment), as the carrier of project information, have the characteristics of nonsynchronization, different resource properties, and mutual restraints [44]. Accordingly, to ensure the efficient coordination of the project and minimize construction costs, the ICPSB-IoT must be able to collect, transmit and process the resource element information to support the information exchange between the users in a timely manner. In addition, the ICPSB-IoT can also track and monitor the quality and supply chains of components. Once problems are uncovered, the alarm will be immediately triggered and the intelligent decision can be made. Moreover, the ICSPB-IoT should integrate technologies such as intelligent algorithms, artificial intelligence, and cloud computing to complete the schematic design of the component production, lifting and distribution (e.g., problems such as component production process, lifting sequence and transportation path optimization). Eventually, the ICPSB-IoT will become an integrated decision service system for the lifecycle data collection, 
processing, and analysis of prefabricated buildings, which will facilitate collaborative operations among contractors.

From the government regulators' standpoint, engineering quality and safety are the bottom lines $[41,45]$. In order to build a safe construction environment, the ICSPB-IoT must be able to visually and trace, in a timely manner, the entire process of construction to ensure that the regulatory department can query the process quality and safety at any time.

\subsection{Establishment of the ICSPB-IoT Framework}

Based on the above demand analysis, the ICSPB-IoT should comprise four systems, namely, the Project-level Information Integration Center (PIIC), IoT-BIM-based Database (IBD), Government Monitoring and Traceability System (GMTS), and Digital Information System for Engineering Products (DISEP).

The PIIC directly collects, classifies, and processes information about the status and attributes of construction resource elements at various stages across project design, manufacturing, transportation, and hoisting, to achieve full transparency of the environment, data and workers' behavior during the construction process. This is an open system with standard data interfaces, and the "plug and play" form makes it applicable to every prefabricated building project. An IoT standard system supporting the intelligent construction of prefabricated buildings must be established firstly, including the unified operation standard, the standard of IoT information collection and transmission, the interaction standard among the participants, etc. Finally, these standards form the ICSPB-IoT standard system to guide participants to adopt the IoT.

The IBD, which is often managed by a third-party supervisor, is often used to regulate the construction process and facilitate information interactions between contractors. It includes two aspects of data, namely industry-standard data related to safety, quality, technology, cost, duration and other design parameters, and real-time data providing decision support for users. Then, the comparative analysis results of the above two data sources are transmitted to the GMTS and the contractors' OA (Office Automation) systems. If there are irregular operations, the regulatory authorities can require prompt corrections. Besides, combined with the two aspects of data, contractors can develop their own subsystems to support their business, such as the material supply management subsystem, project quality traceability subsystem, engineering safety early warning subsystem, component production planning scheduling subsystem, etc. (see Table 3 for detail).

The GMTS established by the government supervision department is the supervision platform of the whole prefabricated buildings industry, which aims to control the quality and safety of the whole process of prefabricated building projects. The system establishes an industry-unified quality and safety database which integrates all aspects of prefabricated building data. The GMTS obtains data on each contractor's subsystems in real-time by interacting with the IBD of the contractors. Then the data are uploaded to the quality and safety database for a comparative analysis. Finally, unqualified work information will be identified and then immediately fed back to the responsible party to find out the cause and corresponding corrections will be required.

The DISEP is a system for the construction of digital engineering products of prefabricated buildings by supervisors. The DISEP obtains first-hand information directly from the PIIC (including materials used, construction process, etc.). Building-related information that is not directly available from the PIIC (e.g., the stress resistance which can only be obtained through experiments conducted by manufacturers) can be obtained through connecting with various contractors through the IBD to ensure that the digital engineering products are true mirror images of the physical products. Then, the owners can query the comprehensive information of prefabricated buildings based on digital engineering products. They only need to click on the product component to trace all attributes from the factory to the final building, such as the compression resistance, bending resistance, and node connection process of the component. Besides, before the completion and acceptance of the building, the contractors can establish a two-way interoperability mechanism between digital engineering products and final 
buildings with the supports of RFID, sensors, AI (Artificial Intelligence) and other IoT technologies. This mechanism can realize the real-time tracking and monitoring of the building status. When faults or quality problems occur, the root cause can be quickly targeted and documented.

Table 3. Subsystem developed by contractors.

\begin{tabular}{|c|c|c|}
\hline Subsystem Owner & Subsystem Name & Function \\
\hline \multirow{2}{*}{ Manufacturer } & $\begin{array}{l}\text { Component Production Planning } \\
\text { Scheduling Subsystem }\end{array}$ & $\begin{array}{l}\text { Collect the information of resource elements in } \\
\text { real-time by using RFID and other sensing } \\
\text { technologies, and dynamically track and optimize } \\
\text { the production activities. }\end{array}$ \\
\hline & $\begin{array}{l}\text { Component Production Quality } \\
\text { Control Subsystem }\end{array}$ & $\begin{array}{l}\text { Integrate the information collected by sensing } \\
\text { devices into the BIM system in a timely manner and } \\
\text { check the parameters of the component production } \\
\text { process to control the quality of components. }\end{array}$ \\
\hline Material supplier & Material Supply Management Subsystem & $\begin{array}{l}\text { Collect and analyze the real-time information of } \\
\text { material supply and inventory on the construction } \\
\text { site to ensure, in a timely manner, that the supply of } \\
\text { materials by using the IoT and intelligent algorithm. }\end{array}$ \\
\hline Logistics carrier & $\begin{array}{l}\text { Component Transportation Dispatch } \\
\text { Management Subsystem }\end{array}$ & $\begin{array}{l}\text { Track and optimize the transport route by using } \\
\text { RFID, GPS and geographic information system (GIS). }\end{array}$ \\
\hline \multirow{3}{*}{ Constructor } & Project Quality Traceability Subsystem & $\begin{array}{c}\text { Upload and analyze the data detected sensors to } \\
\text { control the construction quality by using the IoT and } \\
\text { intelligent algorithm. }\end{array}$ \\
\hline & $\begin{array}{l}\text { Engineering Safety Early } \\
\text { Warning Subsystem }\end{array}$ & $\begin{array}{l}\text { Collect and analyze the information (e.g., working } \\
\text { height, safety facilities, environment) in real-time by } \\
\text { the IoT, and make the early warning according the } \\
\text { danger level. }\end{array}$ \\
\hline & $\begin{array}{l}\text { Construction Site Resource Element } \\
\text { Management Subsystem }\end{array}$ & $\begin{array}{l}\text { Track and collect the resource elements by RFID and } \\
\text { analyze resource requirements systematically to } \\
\text { make optimal resource allocation. }\end{array}$ \\
\hline Designer & Integrated Design Subsystem & $\begin{array}{l}\text { According to the real-time information of the } \\
\text { IoT-BIM-based database, the problems fed back in } \\
\text { the downstream phase are dealt with in a timely } \\
\text { manner to realize the collaboration of } \\
\text { design-manufacturing-construction. }\end{array}$ \\
\hline \multirow{2}{*}{ Supervisor } & $\begin{array}{l}\text { Engineering Digital } \\
\text { Management Subsystem }\end{array}$ & $\begin{array}{l}\text { Proofread the authenticity of building data and build } \\
\text { the digital engineering product according to the } \\
\text { real-time information of IoT-BIM-based database. }\end{array}$ \\
\hline & Monitoring and Early Warning Subsystem & $\begin{array}{l}\text { Monitor and control the quality, safety and progress } \\
\text { of the construction site by combining RFID, machine } \\
\text { vision and other technologies with the IoT. }\end{array}$ \\
\hline
\end{tabular}

Given the above discussion of functional requirements and system composition concerning government regulators, contractors and owners, and in the light of the IoT system in other industries [46], the framework of the ICSPB-IoT is proposed as shown in Figure 1. 


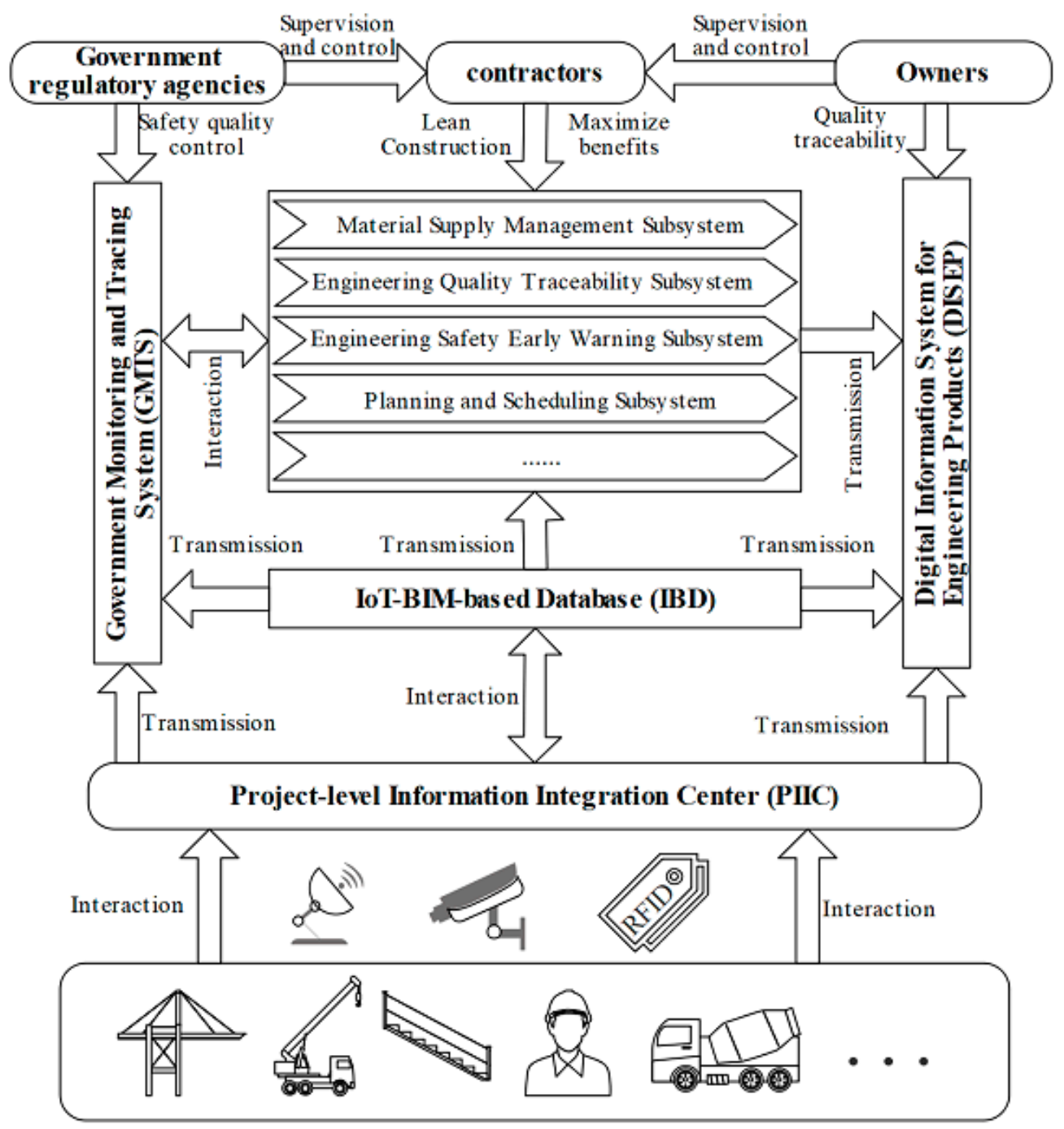

Figure 1. Conceptual framework of Intelligent Construction System for Prefabricated Buildings (ICSPB-IoT).

\section{The Operating Mechanism of the ICSPB-IoT}

Based on the ICPSB-IoT, which has been built and structured in the previous sections, this section will further explore how to operate this system from the perspective of "information flow" to "information network".

\section{1. "Information Flow" to "Information Network"}

An ICSPB-IoT is a complex dynamic system integrating various information flows such as people flow, things flow, and control flow [47]. Moreover, from a vertical perspective, the practice of ICSPB-IoT can be divided into various stages including design, component production, transportation, lifting, and product delivery. The information flows drive the operation of ICSPB-IoT, ensuring the cooperation and coordination across stages and participants, and are critical to the achievement of different goals such as an integrated design, lean production, transparent transportation, and visual assembly. Furthermore, in each stage of the construction process, information flows in two ways, that is, each participant not only transmits information to others, but also obtains information from others.

Under the government-established system of intelligent construction for prefabricated buildings and the IoT industry standard, contractors establish subsystems that receive and transmit information to one another, forming a stream of "information flow". Moreover, the "information flow" is crisscrossed and interwoven to form an "information network", as presented in Figure 2. With the advancement of 
the construction process, the number of participants corresponding to the network nodes increases, and industry standards promote the unification of each node, ensuring the success of information reception and transmission. Compared with the information flow in traditional prefabricated buildings, the "information network" of ICSPB-IoT has real-time dynamics, complete accuracy, traceability and visibility. Based on the ICPSB-IoT "information network", this study further discusses the operation mechanism of the ICPSB-IoT as follows.

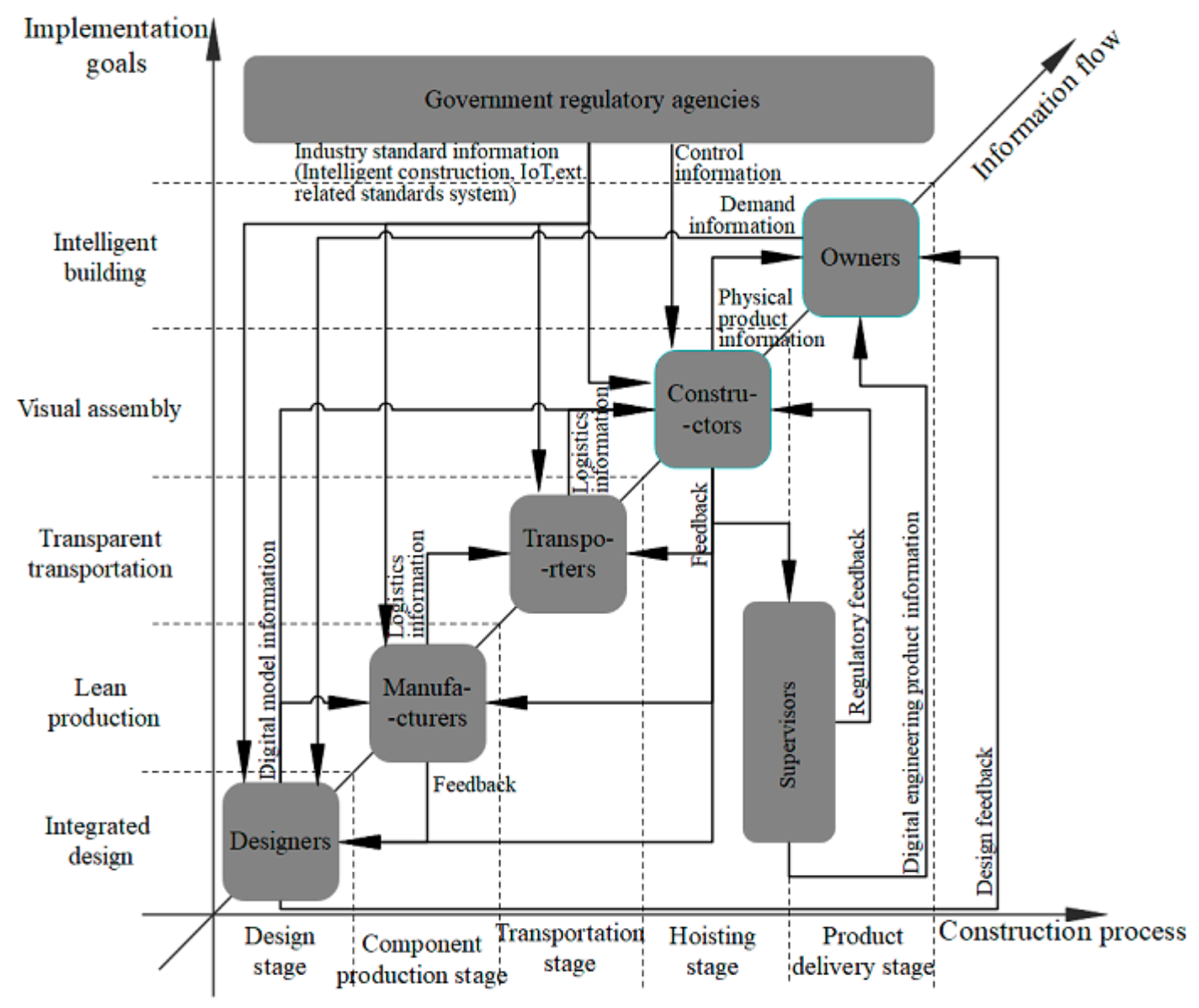

Figure 2. The formation of the ICSPB-IoT "information network".

\subsection{Operating Mechanism}

For the design stage of an ICSPB-IoT, the goal is to coordinate design, manufacturing and construction, as shown in Figure 3. Firstly, according to the owner's needs, a function and performance-oriented approach should be adopted by the designer to develop the design model. Based on this model, a force analysis and collision detection through software (e.g., Glodon and ANSYS) are conducted to generate parameters for the manufacturing and construction in the ICSPB-IoT. Then, manufacturers need to conduct a comparative analysis between the production information of prefabricated components (e.g., materials, production processes, components quality) and design parameters to ensure quality in the manufacturing process. Meanwhile, the constructor should transmit the construction information on-site (e.g., location information of mechanical systems, pipeline and equipment, on-site space collision, on-site construction and design conflicts) comprehensively and accurately in real-time to the integrated design subsystem to facilitate the designer to make technical changes in time. In the environment of the IoT, the information interaction between the entire design, manufacturing and construction processes is realized, which ensures the integrated construction approach of design-manufacturing-assembly. 


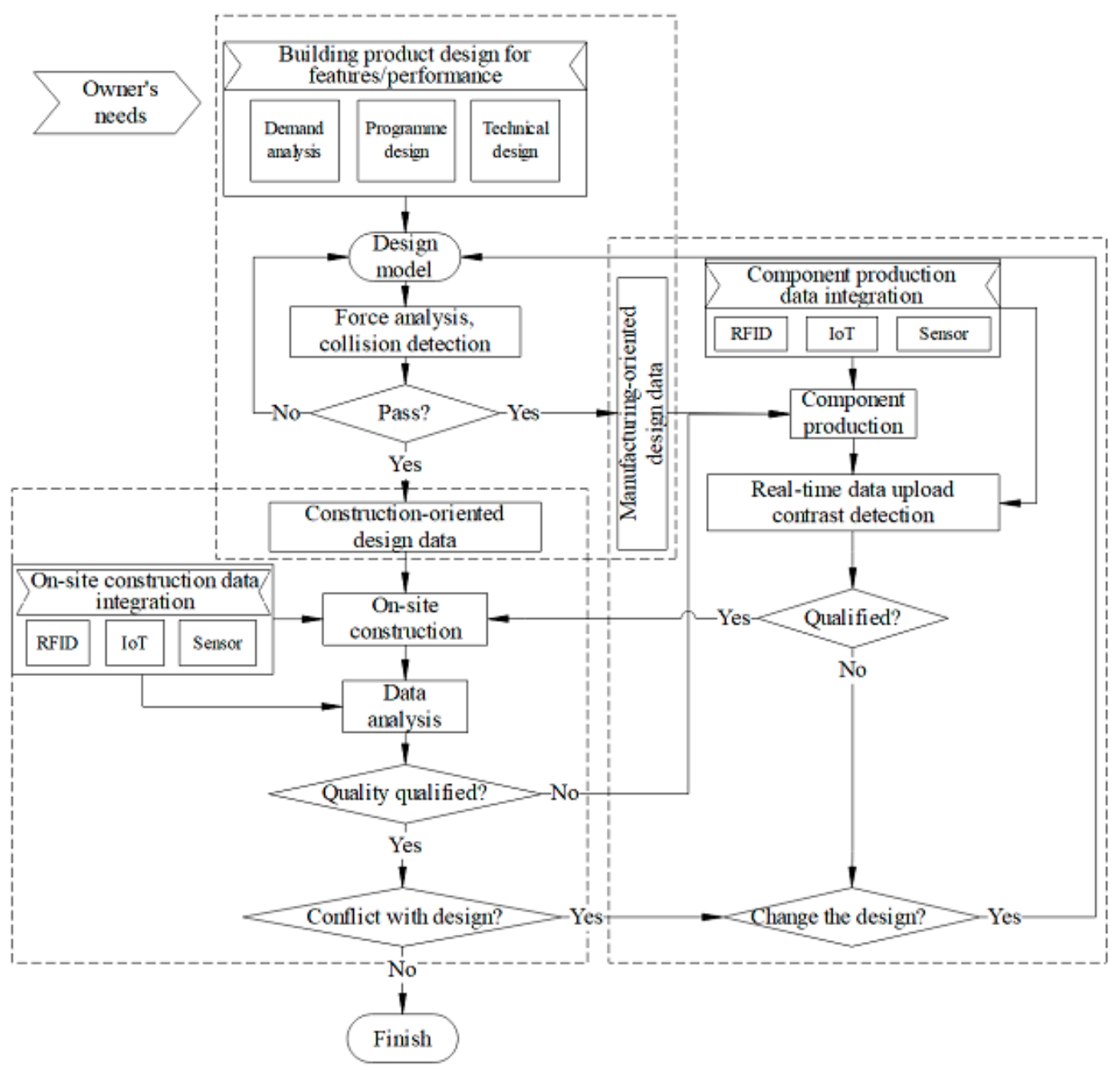

Figure 3. The operating mechanism of ICSPB-IoT in the design stage.

In the component production stage of an ICSPB-IoT, in addition to the quality control system of prefabricated components for collaborative design, manufacturers also need to have a production scheduling system to achieve lean production goals. For example, a lean production system of precast concrete components has been developed by Li et al. [28]. In the context of the IoT, RFID, sensors and other equipment can record the entire process of component production, collecting information in each production process. Then, the quality inspection information of prefabricated components will be transmitted to the IBD, to realize the coordination between upstream design and downstream construction process. In addition, the construction site and workshop information related to the inventory, production process, and resource configuration are integrated into the component production planning scheduling subsystem. Based on this, eight wastes (e.g., overproduction, defects, motion, material movement, waiting, excess inventory, overprocessing, correction) can be eliminated, so as to achieve the goal of maximizing benefits, as shown in Figure 4. 


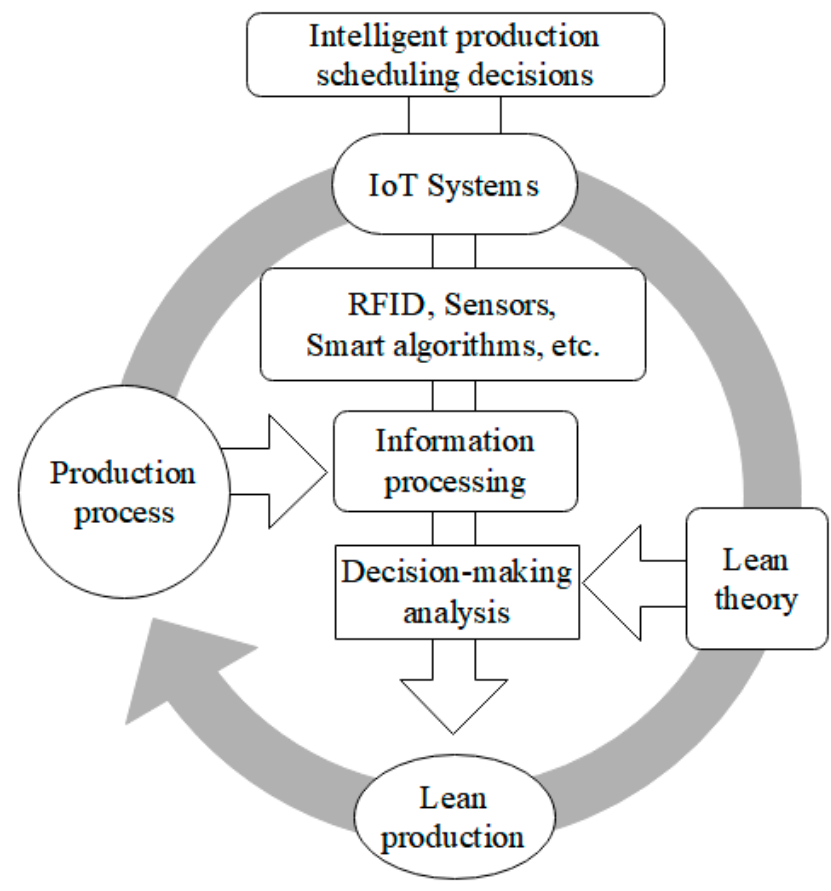

Figure 4. The operating mechanism of ICSPB-IoT in the component production stage.

In the transportation phase, the transparency of real-time information should be achieved. Logistics trucks should be equipped with GPS positioning systems, RFID, sensors and wireless communication systems. Once the electronic waybill is transmitted to the component transportation scheduling management subsystem, the order information will be matched with the information in the cataloguing vehicle, GIS and E-Map to find the best delivery scheme. In addition, in the transportation process, the RFID tag of the vehicle, the building component RFID tag and the driver ID card are connected to the IBD, so that the contractors can obtain the real-time information of vehicle number, driver, cargo list, and driving route. More importantly, the ICSPB-IoT can calculate the estimated arrival time accurately, and then the on-site management staff can initiate the unloading preparation work (e.g., lifting appliances and personnel arrangements, site cleaning, storage space arrangements) according to the arrival time of components to save time.

The on-site hoisting stage gathers almost all participants, including the manufacturer, transporter, supervisor, material supplier, constructor, officer and owner, so the information exchange between various parties is particularly important in this stage. For instance, in order to ensure the quality and safety of construction, the GMTS needs to perform an intelligent analysis of field operations based on the quality and safety database. Meanwhile, besides supervising the site, the supervisors also need to obtain information related to the building quality for setting up the digital engineering product in the DISEP. Besides, the constructors should not only ensure quality and safety, but also accurately control the resource management of the construction site and production plan activities to pursue maximum benefits. The construction site involves the information collection, processing and interaction of high volume, multisource and complex characteristics, which means effective information interactions among project participants are difficult. The ICPSB-IoT offers the possibility to address this issue. First of all, supported by RFID, sensors, GPS and other IoT technologies, the system can transform the construction resource elements into intelligent construction objects (SCOs) that have the characteristics of awareness, communicativeness and autonomy [27]. In addition, the entire information is connected to the construction site resource element management subsystem in real-time. The construction resources are reasonably allocated and scheduled with the principle of cost minimization. Then, the information in the upstream stage (e.g., fabrication process, structural performance, transportation time, etc.), as well as the information on-site (e.g., component quality, hoisting process, node connection, 
material, etc.) are collected and transmitted to the project quality traceability subsystem by using the data transmitter. This facilitates constructors to carry out intelligent on-site management.

Moreover, the safety supervision information of on-site workers, including the working height, the wearing conditions of the seat belts, helmets and safety nets, are transmitted to the engineering safety early warning subsystem in real-time to reduce the occurrence of safety accidents. Finally, these subsystems are connected to the GMTS and the monitoring and early warning system. Once quality problems and hidden safety hazards are discovered, the system will immediately activate the alarm. The entire on-site assembly process is in a visual state. In addition to the constructors' comprehensive management and control of the construction process by using the systems, the government and supervisors can also use the systems to promptly correct inappropriate behaviors that do not meet standards during the construction process, minimizing losses and ensuring the quality.

Concerning the final product delivery stage, its operation mechanism is shown in Figure 5. The supervisors obtain the engineering data corresponding to the physical building from the IBD in real-time, and then the digital engineering products are completed synchronously in DISEP. The constructor uses RFID, sensors, artificial intelligence and other IoT technologies to connect the physical engineering products with the digital engineering products in an all-round manner, including physical space location, quality status, usage, operating status and other information of SCOs, which enables prefabricated buildings to become smart buildings.

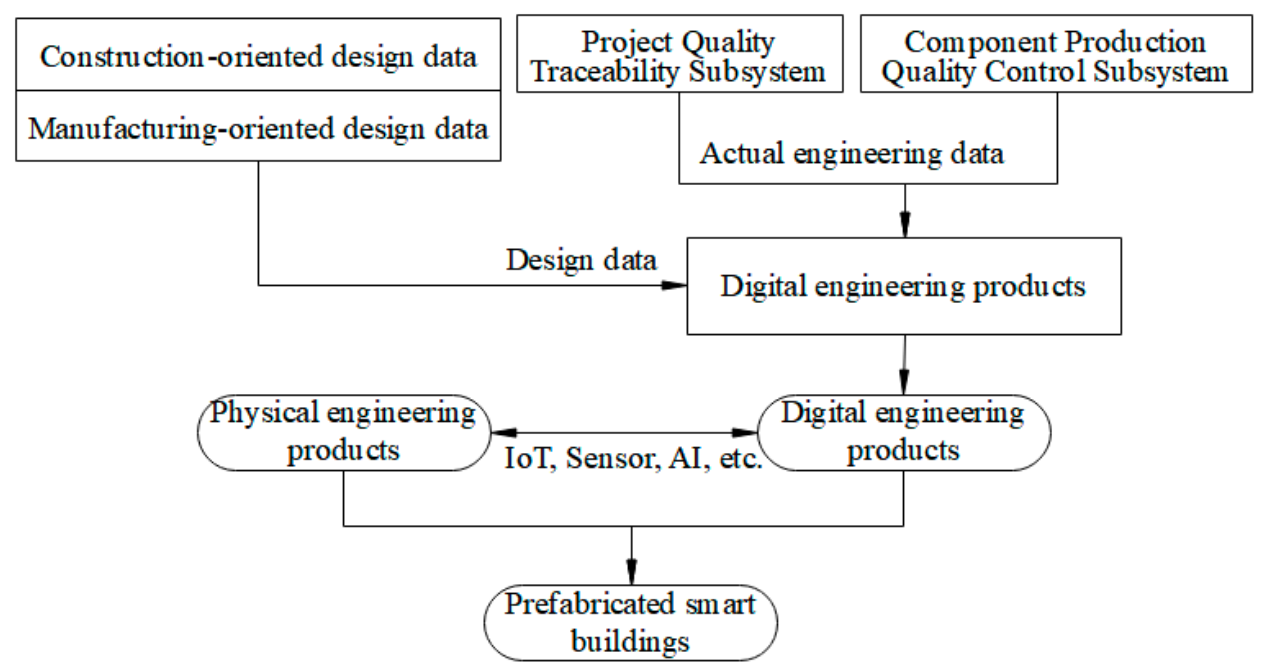

Figure 5. The operation mechanism of ICSPB-IoT in the product delivery stage.

\section{The Implementation Path of the ICSPB-IoT}

\subsection{Implementation Path}

Based on the above operating mechanism, it can be seen that the key of an ICSPB-IoT is to develop an industry chain that integrates with the IoT information chain. From the perspective of the IoT information chain, the ICSPB-IoT can be divided into six systems according to the level of information intelligence [48], including facility system, network integration system, information integration system, data integration system, visual integration system, and application integration system. As shown in Figure 6, enterprises can build the systems according to the following ten steps: 


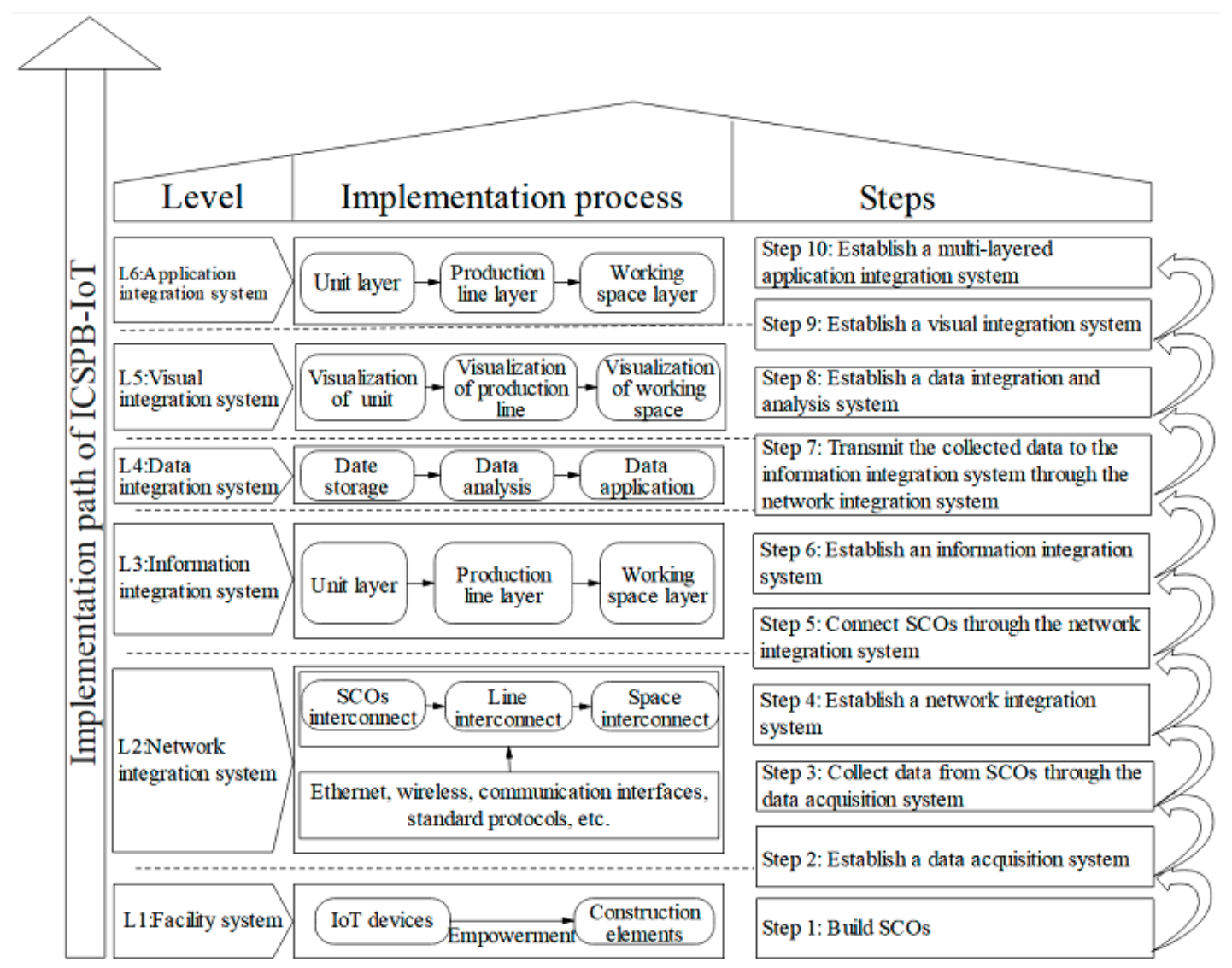

Figure 6. The implementation path of ICSPB-IoT.

Step 1: Build SCOs. Binding construction resource elements to different RFIDs, sensors and other equipment to transform them to SCOs.

Step 2: Establish a data acquisition system, which is used for real-time and automatic collection of data in different work scenarios. PIIC is a part of it.

Step 3: Collect data from SCOs through the data acquisition system.

Step 4: Establish a network integration system to achieve the interconnectivity among unit layers, production line layers, working space layers and enterprise layers. In the unit layer, the signals between SCOs are transmitted through a PLC (Programmable Logic Controller) and the data in the construction process are collected by adopting RFID receivers. The production line layer means that the control system of interconnected SCOs collects data through RFID receivers and then transmits the data to the production line control system by wired optical fiber (Internet) or wireless Internet of Things (such as NB-IoT, Narrow Band Internet of Things). The working space layer mainly refers to the assembly site and fabrication workshop for prefabricated components. Through wired and wireless networks, the working space system is connected to the enterprise system to realize the information interconnection between enterprises. The enterprise layer denotes the connection between the operating systems of the government, contractors and owners and is realized through the Internet.

Step 5: Connect SCOs through the network integration system.

Step 6: Establish an information integration system. Achieving information interoperability between the unit layer, production line layer, working space layer, and enterprise layer ultimately enables contractors to operate, process, and analyze information from subsystem to subsystem. The information system at the unit layer mainly includes the SCOs control system, the SCOs management system and the data acquisition system which can be integrated with the construction process, materials, transportation and storage information systems at the production line layer through intelligent gateways and PLCs. This realizes the production material supply management, component production quality 
management, and construction schedule management. The information system at the working space layer includes the manufacturing execution system, logistics execution system and on-site assembly execution system. The enterprise layer information system mainly includes the GMTS and DISEP.

Step 7: Transmit the collected data to the information integration system through the network integration system.

Step 8: Establish a data integration and analysis system. The collected data are stored in the IBD and transferred to contractors' subsystems for analysis.

Step 9: Establish a visual integration system. Enterprises could build transparent and visual management display platforms for the entire system from the perspective of the unit layer, production line layer and working space layer.

Step 10: Establish a multilayered application integration system. The unit layer is utilized to analyze and control the operating state for SCOs. The production line layer is used for the optimization, testing and analysis of the production line. The working space layer is the control and management system of the smart construction site or intelligent workshop. The enterprise layer system mainly manages and controls the information that the government, contractors and owner value.

\subsection{Discussion}

In essence, building information management can be regarded as a process of driving intelligent construction based on available information. The existing industrial intelligent systems generally include three dimensions: lifecycle dimension, system hierarchy dimension and intelligent feature dimension [49]. The ICPSB-IoT is an integrated decision-supporting system for full lifecycle data collection, processing, and analysis of prefabricated buildings. The decision-making service is related to the specific service requirements of the engineering application. For different users, the content of the service and the required decision-making subsystem are also different [50]. In comparison, an ICSPB-IoT is more comprehensive, which is suitable for the needs of the government, contractors and owners. The tripartite project level engineering information is mostly derived from the PIIC and IBD to ensure the unity of the data source. Meanwhile, SCOs at the unit layer of ICSPB-IoT can enhance the functionality of the BIM [27]. The SCOs can collect information, in a timely manner, on the physical status and surrounding environment with awareness and communication, which could actively, frequently, and accurately synchronize construction and production information with BIM elements, laying the foundation for the interoperability of the ICSPB-IoT. In addition, the main systems and subsystems of ICSPB-IoT are interconnected, with the functions of receiving/transmitting, controlling, debugging and storing. They can be regarded as network "nodes" and extension components of the construction IoT. SCOs, as construction resources augmented with AI, are the basic components of the construction IoT [27]. In the IoT paradigm, the connections of SCOs, subsystems and systems can be established based on specific mechanisms or protocols [7]. Once the network system is established, as SCOs continuously sense, record and share real-time information, the subsystem connected to SCOs will also be activated in the ICSPB-IoT. Eventually, the ICSPB-IoT network composed of subsystems can remain active. The IoT shared services at all stages (e.g., integrated design, lean production, transparent transportation, visual assembly, and intelligent building) can be realized based on the ICSPB-IoT between different parties.

It is foreseeable that ICSPB-IoT will gradually achieve industry standardization and enter the market in the future, forming a complete ecosystem. However, there are still many challenges to overcome. The first challenge is interoperability. System programs in different environments should interoperate and exchange information at all layers, including the unit layer SCOs, the production line layer subsystem, the working space system, and the enterprise layer systems. The intelligence of the system largely depends on the ability of information exchange between them. The highly dispersed nature of buildings leads to the increase in system diversity, and it is tough for a single enterprise to guide the industry to achieve technological progress [51]. The device deployments are usually decentralized and mixed, which is a potential challenge for achieving the interoperability of 
an ICSPB-IoT [52]. Secondly, for the construction industry, it has been slow in the adoption of new technologies. Before receiving obvious benefits, companies will particularly hesitate to invest in this area $[53,54]$. This conservative approach will hinder the study and adoption of ICSPB-IoT. Additionally, an ICSPB-IoT is a complex system with multiple subsystems. As the number of devices connected to the communication network increases, the security and privacy issues of the system become potential challenges [52]. The security of the IoT system depends on the technology, protocols and security mechanisms implemented by the system and equipment, and any system may be subject to certain types of attacks [55]. Strong security standards and mechanisms should be developed for ICSPB-IoT in time to respond to emerging threats.

\section{Conclusions}

This paper firstly proposes a conceptual framework for an ICSPB-IoT by considering the application needs of government, contractors and owners. On this basis, this paper investigates the operation mechanism of an ICSPB-IoT at various stages from integrated design, lean manufacturing, transparent transportation, to intelligent construction. Finally, according to the IoT information chain, this paper divides the ICSPB-IoT into six levels and ten steps and builds the system according to the path from the unit layer, production line layer, workspace layer, to the enterprise layer. The results show that the ICSPB-IoT framework, subsystems and development paths proposed in this paper can provide decision support for construction enterprises and governments and provide references for improving and perfecting the intelligent construction system.

This study has theoretical and practical contributions to existing knowledge. Theoretically, the ICSPB-IoT is based on existing research to improve the lifecycle information management of prefabricated buildings. First, the framework and system of the ICSPB-IoT proposed in this paper provide an integrated service platform for users of prefabricated buildings. Then, by analyzing the flow of information in each stage, this paper expounds on the operation mechanism of ICSPB-IoT to improve the collaboration and communication ability between users. Finally, the development path of the ICSPB-IoT proposed in this article provides a reference for application developers. In practice, an ICSPB-IoT is a system that serves the cross-stage, cross-organizational cooperation and collaboration of all participants in prefabricated buildings to achieve goals at various stages such as integrated design, lean production, transparent transportation, visual assembly, and intelligent architecture. In addition, government departments can visually monitor the quality and safety of projects based on the ICSPB-IoT. Furthermore, contractors can not only share information, but also further control their own business based on the subsystem of the ICSPB-IoT. For owners, ICSPB-IoT can provide digital engineering products corresponding to the building, tracking the quality and equipment in operation and maintenance stage of the building. Although different countries have distinctive systems and cultures-this paper takes China as an example to classify the participants-the service objects of the ICSPB-IoT covers almost all participants of prefabricated buildings, which in fact provides a framework for information sharing throughout the construction process. The stages and management tasks of prefabricated construction projects are similar in other countries. Thus, they can apply ICSPB-IoT to facilitate information sharing between organizations during construction according to their respective engineering management ways. For example, Europe and the America are powerful countries in industrialization and information technology in the world, their prefabricated buildings urgently need information systems to promote the development of integration. Governments, public agencies or housing associations of Europe and America can refer to the research model in this paper to realize the informatization of the prefabricated buildings construction chain.

This study attempts to explore the development of ICSPB-IoT. At present, this field of research is still in its infancy. Therefore, there are several limitations to be further studied in the future. First, the effectiveness and practicability of the ICSPB-IoT proposed in this paper need to be investigated in practice. Future studies could be carried out from the following aspects: (1) Research on the construction and integration of subsystems based on the full lifecycle of prefabricated buildings, including the 
integration and collaboration of systems between design, manufacturing, supply, assembly and service. For example, the digital engineering products servicing the owners can be realized by using the digital twin, which has a research foundation in the manufacturing field [56]. (2) Integrate industry standards of prefabricated buildings into ICSPB-IoT to standardize the operations, behaviors and data formats of the system to further improve the efficiency of construction.

Author Contributions: Conceptualization, X.W., S.W. and X.S.; Methodology, X.W., S.W. and X.S.; Analysis, X.W., S.W., X.S. and Y.H.; Writing-Original Draft Preparation, S.W. and X.S.; Writing-Review and Editing, X.W., X.S. and Y.H.; Project Administration, X.W., X.S. and Y.H.; Funding Acquisition, X.W., S.W., X.S. and Y.H. All authors have read and agreed to the published version of the manuscript.

Funding: The authors gratefully acknowledge the Humanities and Social Sciences Projects of Ministry of Education (Grant No. 18YJA630113), the Humanities and Social Sciences Projects of Guangdong General Universities (Grant No. 2017WTSCX097), the Guangzhou University Graduate Innovation Capacity Development Grant Program (Grant No. 2019GDJC-M48), and the Major projects of the National Social Science Fund of China (Grant No. 18ZDA043) for providing support to this research effort.

Conflicts of Interest: The authors declare no conflict of interest.

\section{References}

1. Liu, P.; Li, Q.; Song, L.; Jia, R. The index system for the development level evaluation of regional construction industrialization: A Case Study in Jiangsu, China. Appl. Sci. 2017, 7, 492. [CrossRef]

2. Li, Z.; Shen, G.Q.; Xue, X. Critical review of the research on the management of prefabricated construction. Habitat Int. 2014, 43, 240-249. [CrossRef]

3. Lu, L.Q. Report of Development Pattern and Investment Strategy Planning on China Residence Industrialization (2018-2023). 2018. Available online: https://www.qianzhan.com/analyst/detail/220/18010941af947e.html (accessed on 9 January 2018).

4. Research and Markets. Prefabricated Building Market-Global Outlook and Forecast 2020-2025. 2020. Available online: https://www.researchandmarkets.com/reports/5011317/prefabricated-building-marketglobal-outlook?utm_source=dynamic\&utm_medium=CI\&utm_code=vgrbt4\&utm_campaign=1376992+ -+Global+Prefabricated+Building+Market+Insights+by+Application \%2c+Material\%2c+System +and+ GeograGeo+-+Forecast+to+2025\&utm_exec=joca220cid (accessed on 14 April 2020).

5. Ji, Y.; Zhu, F.; Li, H.; Al-Hussein, M. Construction Industrialization in China: Current Profile and the Prediction. Appl. Sci. 2017, 7, 180. [CrossRef]

6. Xu, G.; Li, M.; Chen, C.; Wei, Y. Cloud asset-enabled integrated IoT platform for lean prefabricated construction. Autom. Constr. 2018, 93, 123-134. [CrossRef]

7. Perumal, T.; Ramli, A.R.; Leong, C.Y.; Samsudin, K.; Mansor, S. Middleware for heterogeneous subsystems interoperability in intelligent buildings. Autom. Constr. 2010, 19, 160-168. [CrossRef]

8. Li, X.; Li, Z.; Wu, G. Lean Precast Production System based on the CONWIP Method. KSCE J. Civ. Eng. 2018, 22, 2167-2177. [CrossRef]

9. Lai, H.; Deng, X.; Chang, T.Y.P. BIM-based platform for collaborative building design and project management. J. Comput. Civ. Eng. 2019, 33, 05019001. [CrossRef]

10. Li, C.Z.; Zhong, R.Y.; Xue, F.; Xu, G.; Chen, K.; Huang, G.G.; Shen, G.Q. Integrating RFID and BIM technologies for mitigating risks and improving schedule performance of prefabricated house construction. J. Clean. Prod. 2017, 165, 1048-1062. [CrossRef]

11. Fang, Y.; Cho, Y.K.; Zhang, S.; Perez, E. Case study of bim and cloud-enabled real-time rfid indoor localization for construction management applications. J. Constr. Eng. Manag. 2016, 142, 05016019. [CrossRef]

12. Ergen, E.; Akinci, B.; Sacks, R. Tracking and locating components in a precast storage yard utilizing radio frequency identification technology and GPS. Autom. Constr. 2007, 16, 354-367. [CrossRef]

13. Zhong, R.Y.; Huang, G.Q.; Lan, S.; Dai, Q.Y.; Xu, C.; Zhang, T. A big data approach for logistics trajectory discovery from RFID-enabled production data. Int. J. Prod. Econ. 2015, 165, 260-272. [CrossRef]

14. Zhong, R.Y.; Peng, Y.; Xue, F.; Fang, J.; Zou, W.; Luo, H.; Ng, S.T.; Lu, W.; Shen, G.Q.P.; Huang, G.Q. Prefabricated construction enabled by the Internet-of-Things. Autom. Constr. 2017, 76, 59-70. [CrossRef]

15. Maskuriy, R.; Selamat, A.; Ali, K.N.; Maresova, P.; Krejcar, O. Industry 4.0 for the construction industry-How ready is the industry? Appl. Sci. 2019, 9, 2819. [CrossRef] 
16. Craveiro, F.; Duarte, J.P.; Bartolo, H.G.; Bartolo, P.J. Additive manufacturing as an enabling technology for digital construction: A perspective on Construction 4.0. Autom. Constr. 2019, 103, 251-267. [CrossRef]

17. Ding, L.Y. Intelligent Construction Promotes the Transformation of the Construction Industry; China Construction News: Beijing, China, 2019. Available online: http://www.chinajsb.cn/html/201906/10/3522.html (accessed on 10 June 2019).

18. Singh, A.; Payal, A.; Bharti, S. A walkthrough of the emerging IoT paradigm: Visualizing inside functionalities, key features, and open issues. J. Netw. Comput. Appl. 2019, 143, 111-151. [CrossRef]

19. Sun, Q.B.; Liu, J.; Li, S.; Fan, C.X.; Sun, Z.Z. Internet of Things: Summarize on Concepts, Architecture and Key Technology Problem. J. Beijing Univ. Posts Telecommun. 2010, 3, 1-9. (In Chinese) [CrossRef]

20. Liu, D.; Lu, W.; Niu, Y. Extended technology-acceptance model to make smart construction systems successful. J. Constr. Eng. Manag. 2018, 144, 04018035. [CrossRef]

21. Yin, S.Y.L.; Tserng, H.P.; Wang, J.C.; Tsai, S.C. Developing a precast production management system using RFID technology. Autom. Constr. 2009, 18, 677-691. [CrossRef]

22. Wang, Z.; Hu, H. Improved precast production-scheduling model considering the whole supply chain. J. Comput. Civ. Eng. 2017, 31, 04017013. [CrossRef]

23. Wang, M.; Altaf, M.S.; Al-Hussein, M.; Ma, Y. Framework for an IoT-based shop floor material management system for panelized homebuilding. Int. J. Constr. Manag. 2020, 20, 130-145. [CrossRef]

24. Wang, L.J.; Huang, X.; Zheng, R.Y. The application of BIM in intelligent construction. Appl. Mech. Mater. 2012, 188, 236-241. [CrossRef]

25. De, S.B.G.; Agusti-Juan, I.; Hunhevicz, J.; Joss, S.; Graser, K.; Habert, G.; Adey, B. Productivity of digital fabrication in construction: Cost and time analysis of a robotically built wall. Autom. Constr. 2018, 92, $297-311$. [CrossRef]

26. Woodhead, R.; Stephenson, P.; Morrey, D. Digital construction: From point solutions to IoT ecosystem. Autom. Constr. 2018, 93, 35-46. [CrossRef]

27. Niu, Y.; Lu, W.; Chen, K.; Huang, G.G.; Anumba, C. Smart Construction Objects. J. Comput. Civ. Eng. 2016, 30, 04015070. [CrossRef]

28. Li, C.Z.; Xue, F.; Li, X.; Hong, J.; Shen, G.Q. An Internet of Things-enabled BIM platform for on-site assembly services in prefabricated construction. Autom. Constr. 2018, 89, 146-161. [CrossRef]

29. Cho, C.; Kwon, S.; Shin, T.; Chin, S.; Kim, Y. A development of next generation intelligent construction liftcar toolkit for vertical material movement management. Autom. Constr. 2011, 20, 14-27. [CrossRef]

30. Tae-Hong, S.; Sangyoon, C.; Su-Won, Y.; Soon-Wook, K. A service-oriented integrated information framework for RFID/WSN-based intelligent construction supply chain management. Autom. Constr. 2011, 20, 706-715. [CrossRef]

31. Da, X.L.; He, W.; Li, S. Internet of Things in industries: A survey. IEEE Trans. Ind. Inform. 2014, 10, $2233-2243$. [CrossRef]

32. Chen, Y. Industrial information integration-A literature review 2006-2015. J. Ind. Inf. Integr. 2016, 2, 30-64. [CrossRef]

33. Cheng, Y.; Chen, K.; Sun, H.; Zhang, Y.; Tao, F. Data and knowledge mining with big data towards smart production. J. Ind. Inf. Integr. 2018, 9, 1-13. [CrossRef]

34. Ma, G.; Jiang, J.; Shang, S. Visualization of component status information of prefabricated concrete building based on building information modeling and radio frequency identification: A case study in China. Adv. Civ. Eng. 2019, 2019, 1-13. [CrossRef]

35. Du, J.; Sugumaran, V.; Gao, B. RFID and Multi-Agent Based Architecture for Information Sharing in Prefabricated Component Supply Chain. IEEE Access 2017, 5, 4132-4139. [CrossRef]

36. Hu, M.; Lu, J. An Intelligent System for Precast Concrete Element Manufacturing Management Based on RFID Technology. In Proceedings of the 2013 IEEE International Conference on Green Computing and Communications and IEEE Internet of Things and IEEE Cyber, Physical and Social Computing, Washington, DC, USA, 20-23 August 2013; pp. 1138-1143. [CrossRef]

37. Zhou, H.; Wang, H.; Zeng, W. Smart construction site in mega construction projects: A case study on island tunneling project of Hong Kong-Zhuhai-Macao Bridge. Front. Eng. Manag. 2018, 5, 78-87. [CrossRef]

38. Yu, Z.; Peng, H.; Zeng, X.; Sofi, M.; Xing, H.; Zhou, Z. Smarter construction site management using the latest information technology. Proc. Inst. Civ. Eng. Civ. Eng. 2019, 172, 89-95. [CrossRef] 
39. Kim, C.; Park, T.; Lim, H.; Kin, H. On-site construction management using mobile computing technology. Autom. Constr. 2013, 35, 415-423. [CrossRef]

40. Kochovski, P.; Stankovski, V. Supporting smart construction with dependable edge computing infrastructures and applications. Autom. Constr. 2018, 85, 182-192. [CrossRef]

41. Zhang, X.; Skitmore, M.; Peng, Y. Exploring the challenges to industrialized residential building in China. Habitat Int. 2014, 41, 176-184. [CrossRef]

42. Minoli, D.; Sohraby, K.; Occhiogrosso, B. IoT Considerations, Requirements, and Architectures for Smart Buildings-Energy Optimization and Next-Generation Building Management Systems. IEEE Internet Things J. 2017, 4, 269-283. [CrossRef]

43. Tetik, M.; Peltokorpi, A.; Seppänen, O.; Holmström, J. Direct digital construction: Technology-based operations management practice for continuous improvement of construction industry performance. Autom. Constr. 2019, 107, 102910. [CrossRef]

44. Chen, W.; Qin, H.; Tong, M.; Chen, W.; Qin, H.; Tong, M. Resource scheduling for prefabricated building based on multi-dimensional working areas. China Civ. Eng. J. 2017, 50, 115-122. (In Chinese) [CrossRef]

45. Huang, X.; Hinze, J. Analysis of Construction Worker Fall Accidents. J. Constr. Eng. Manag. 2003, 129, $262-271$. [CrossRef]

46. Wang, X.H.; Zhang, Q.L. Construction of Cold-Chain Logistics System for Fresh Agricultural Products Based on the Internet of Things: Framework, Mechanism and Path. J. Nanjing Agric. Univ. 2016, 16, 31-41. (In Chinese)

47. Cao, X.Y.; Yan, Y.Z.; Bao, Y.H.; You, B.Y. Research on Application of BIM Technology in Information Collaboration of Prefabricated Building. Constr. Econ. 2019, 40, 85-89. (In Chinese) [CrossRef]

48. Zhang, X.; Ming, X.; Liu, Z.; Qu, Y.; Yin, D. An overall framework and subsystems for smart manufacturing integrated system (SMIS) from multi-layers based on multi-perspectives. Int. J. Adv. Manuf. Technol. 2019, 103, 703-722. [CrossRef]

49. Li, X.; Li, D.; Wan, J.; Vasilakos, A.V.; Lai, C.F.; Wang, S. A review of industrial wireless networks in the context of Industry 4.0. Wirel. Netw. 2017, 23, 23-41. [CrossRef]

50. Zhu, H.H.; Li, X.J.; Lin, X.D. Infrastructure Smart Service System (iS3) and its application. China Civ. Eng. J. 2018, 51, 1-12. (In Chinese) [CrossRef]

51. Flanagan, R.; Jewell, C.; Lu, W.; Pekericli, K. Auto-ID—Bridging the Physical and the Digital on Construction Projects; Chartered Institute of Building: Berkshire, UK, 2014; ISBN 1853800191.

52. Elkhodr, M.; Shahrestani, S.; Cheung, H.N. The Internet of Things: New Interoperability, Management and Security Challenges. Int. J. Netw. Secur. Appl. 2016, 8, 85-102. [CrossRef]

53. Jia, Z.; Li, Z.F.; Miao, C.Q.; Liang, D.L. Barriers and Coping Strategies of Information Technology Implementation in Chinese Construction Enterprises. Inf. Technol. J. 2013, 12, 8191-8195. [CrossRef]

54. Stewart, R.A.; Mohamed, S.; Marosszeky, M. An empirical investigation into the link between information technology implementation barriers and coping strategies in the Australian construction industry. Constr. Innov. Inf. Process Manag. 2004, 4, 155-171. [CrossRef]

55. Yang, Y.; Wu, L.; Yin, G.; Li, L.; Zhao, H. A Survey on Security and Privacy Issues in Internet-of-Things. IEEE Internet Things J. 2017, 4, 1250-1258. [CrossRef]

56. Zhuang, C.B.; Liu, J.H.; Xiong, H.; Ding, X.Y.; Liu, S.L.; Weng, G. Connotation, architecture and trends of product digital twin. Comput. Integr. Manuf. Syst. 2017, 23, 753-768. (In Chinese) [CrossRef]

(C) 2020 by the authors. Licensee MDPI, Basel, Switzerland. This article is an open access article distributed under the terms and conditions of the Creative Commons Attribution (CC BY) license (http://creativecommons.org/licenses/by/4.0/). 